\title{
FIELD EVALUATION OF THE WHOLE BLOOD IMMUNOCHROMATOGRAPHIC TEST FOR RAPID BANCROFTIAN FILARIASIS DIAGNOSIS IN THE NORTHEAST OF BRAZIL
}

\begin{abstract}
SUMMARY
This study evaluated the whole blood immunochromatographic card test (ICT card test) in a survey performed in Northeastern Brazil. 625 people were examined by the thick blood film (TBF) and ICT card test. Residents of a non-endemic area were also tested by the whole blood card test and $\mathrm{Og} 4 \mathrm{C} 3$. The sensitivity of the ICT card test was $94.7 \%$ overall, but lower in females than males, based on the reasonable assumption that TBF is $100 \%$ specific. However, since TBF and other methods have unknown sensitivity, the true specificity of the card test is unknown. Nevertheless, it is possible to estimate upper and lower limits for the specificity, and relate it to the prevalence of the disease. In the endemic area, the possible range of the specificity was from $72.4 \%$ to $100 \%$. $29.6 \%$ of the card tests performed in the non-endemic area exhibited faint lines that were interpreted as positives.
\end{abstract}

Characteristics of the method including high sensitivity, promptness and simplicity justify its use for screening of filariasis. However, detailed information about the correct interpretation in case of extremely faint lines is essential. Further studies designed to consider problems arising from imperfect standards are necessary, as is a sounder diagnostic definition for the card test.

KEYWORDS: Bancroftian filariasis; Diagnostic; Screening; Surveillance.

\section{INTRODUCTION}

Lymphatic filariasis remains a considerable cause of clinical morbidity and disability in many developing countries. Among the 120 million estimated cases of the disease in the world, Wuchereria bancrofti is responsible for approximately $90 \%{ }^{14}$. Despite the magnitude of the problem, some characteristics such as inefficient transmission, absence of a non-human reservoir for $W$. bancrofti, and new treatment schemes, have led WHO experts to consider the possibility of disease elimination worldwide $^{1}$. To achieve this goal, improvements in the filarial control strategies in terms of planning, execution and monitoring of interventions programs are necessary. In this context, the introduction of new technologies to provide rapid and accurate identification of infection and transmission is a significant element to be accomplished ${ }^{14}$.

Bancroftian filariasis surveys using thick blood film (TBF), the usual diagnostic method, have several problems. First, the need to collect blood during the night often results in refusals and increased costs. Second, the sensitivity of the method is relatively low, leading to misdiagnoses of people with low-density infections and consequently allowing them to progress to irreversible major lymphatic damages. The immunochromatographic method (AMRAD ICT, New South Wales, Australia), specially developed for the diagnosis of bancroftian filariasis in human serum or plasma, has shown various advantages when compared to the TBF. Besides the simplicity of daytime blood collection, the ICT card test has demonstrated high sensitivity and specificity when performed in serum ${ }^{2,8,11,13,16,22,26}$.

Recently, a generation of ICT card test to be performed in whole blood samples has been produced. In addition to the advantages exhibited by the previous version, it can conveniently be performed on finger prick blood samples without requiring any laboratory procedures and yields results in a few minutes. These significant features make the whole blood ICT card test a potential diagnostic tool to be adopted in screening and surveillance of bancroftian filariasis risk areas. However, studies evaluating this new test in fieldwork are still scarce $\mathrm{e}^{6,12,15,17}$ and the study designs applied can place some limitation on the applicability of these results to different groups of individuals ${ }^{20,23}$.

This study aimed to evaluate the validity of the whole blood ICT card test in a survey carried out in an endemic area in North-eastern Brazil. The specificity of the test was also evaluated in residents of a non-endemic area.

\section{MATERIAL AND METHODS}

Study population: Although most of the bancroftian filariasis endemic areas in Brazil in the last century are considered extinct, the

Financial support: OPAS(ASC-97/00188-0) and FACEPE (APQ-0095-4.06/98).

(1) Centro de Pesquisas Aggeu Magalhães, Fundação Oswaldo Cruz, Recife, Pernambuco, Brazil.

(2) Instituto de Saúde Coletiva, Universidade Federal da Bahia, BA, Brazil.

(3) Departamento de Medicina Tropical, Universidade Federal de Pernambuco, PE, Brazil.

(4) London School of Hygiene and Tropical Medicine, London University, UK.

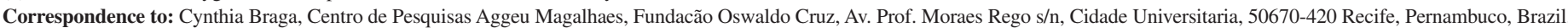
e-mail: braga@cpqam.fiocruz.br 


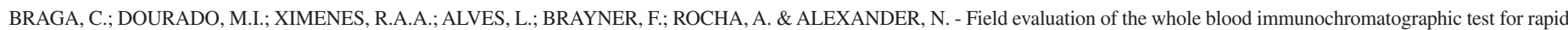
bancroftian filariasis diagnosis in the northeast of Brazil. Rev. Inst. Med. trop. S. Paulo, 45(3):125-129, 2003.

states of Pernambuco and Alagoas, located in the Northeastern Region, still remain as transmission areas ${ }^{5,9}$. The tropical climate, characterised by warm temperatures and high humidity, allows a short life cycle for Culex quinquefasciatus, the sole vector of bancroftian filariasis in Brazil ${ }^{4}$. In addition, lack of sanitation in some urban areas has favoured the proliferation of breeding sites.

The study was performed in the city of Olinda, Pernambuco, as part of a bancroftian filariasis baseline survey carried out from May to September of $1999^{3}$. The study population was selected by two-stage cluster sampling. First, a systematic sample of the census districts was obtained. Second, a systematic sample of the households within each district was selected. The selection of the households was carried out in the districts, going through the census districts in a clockwise direction. Every 30th household counted during the itinerary was chosen and a total of 3,885 people aged between 5 and 65 years living in these households were eligible for the parasitological survey. A sub-sample constituting all people living in each 5th household sampled for the survey was asked to be examined by both TBF and whole blood ICT card test. Moreover, all members of households that had a person with a positive result by the TBF were re-checked by the ICT card test.

In order to validate the card test, a non-endemic area was studied. A group of residents of Campina Grande, a non-endemic area, composed of $74(67.3 \%)$ patients attending in the local University Hospital laboratory, $20(18.2 \%)$ of a private laboratory and $16(14.5 \%)$ blood donors, were asked to participate. The city was chosen because it is placed in a neighbouring state, Paraiba, and is $190 \mathrm{~km}$ away from Olinda, the nearest endemic focus of filariasis. Furthermore, its semi-arid climate does not permit the transmission of the disease by Culex quinquefasciatus. Two parasitological surveys carried out in 1955 and 1974 did not register any autochthonous cases in the region ${ }^{18}$. For the current study, a questionnaire was applied and informations about birthplace, history of travelling and/or place of residence were obtained to check that no one had lived in or visited endemic areas in the previous five years.

Ethical procedures: The project was submitted and approved by the Ethical Committee of the Centro de Pesquisas Aggeu Magalhaes. All participants were informed about the objectives of the study and asked to sign an informed consent.

Blood collection: The nocturnal blood collection in the endemic area was performed between 9 and 12 p.m. by a trained team. In the subsample constituted by each 5 th household selected for the baseline survey, two separate finger-prick blood samples of approximately $60 \mu \mathrm{l}$ (three drops) were collected from all individuals to carry out both the TBF and ICT card test. The first sample was drawn onto a microscope slide, and the second was dropped onto an ICT card according to the manufacturer's instructions. Moreover, all members of the households that had a person with a positive TBF in the baseline survey were asked to have a second nocturnal finger blood collection to perform the ICT card test.

For participants in the non-endemic area, $2 \mathrm{ml}$ of blood were collected between 7 a.m. and 1 p.m. when a venous puncture was being carried out for other tests. Briefly, three drops of blood were taken from the syringe onto the test card. In order to confirm their negative status, the remainder of the blood sample was centrifuged and the serum used to perform Og4C3-ELISA (TropBio, Townsville, Australia), a highly sensitive and specific method for diagnosis of bancroftian filariasis ${ }^{19}$.

\section{Description of the techniques and laboratory procedures}

Thick blood film: This method detects Wuchereria bancrofti larval forms through finger prick blood samples collected during the time of peak microfilaraemia. The identification of the microfilariae $(\mathrm{mf})$ in the blood stream is the definitive method of the diagnostic of infection, although the microfilaraemia load must be sufficient to permit its detection in the volume of blood examined. Considering the blood sample size used in the study, a reasonable sensitivity for the thick blood film is only obtained when the microfilariae density is $20 \mathrm{mf} / \mathrm{ml}^{10}$.

A rectangular smear covering an area of approximately $80 \%$ of the slide was left to dry overnight at room temperature and read the next day. The slides were dehaemoglobinized in water, fixed in methanol for 3 min, stained with haematoxylin (Carrazi method) and examined microscopically ${ }^{27}$.

ICT card test (AMRAD ICT, New South Wales, Australia): The test uses paired antibodies (polyclonal and monoclonal antibodies) that recognises filarial antigen in the blood of infected humans. The antigen (or antigens) bound by monoclonal antibody (AD12) have not been entirely characterised, but they seem to be found in all stages of Wuchereria bancrofti ${ }^{10}$. The cards were stored in a refrigerator at $8{ }^{\circ} \mathrm{C}$ and carried to the field in polystyrene foam boxes. The reading and interpretation of the tests in the endemic area was performed the next day by an independent team. Cards exhibiting the control line were considered valid. The reading and interpretation of the results followed the manufacturer's instruction that states, "Any visible line in the T area [test line] indicates a positive result. The test is positive even when the T line appears lighter or darker than C [control] line". In the non-endemic area, the tests were read 15 minutes after dropping the blood onto the card, by two examiners who took part in interpreting the results in the endemic area. In addition, a third examiner reread the exams the following week.

Og4C3-ELISA: This assay contains a monoclonal antibody (Og4C3) and has the same principles as the ICT card test ${ }^{10}$. The test was developed on serum specimens. All results were tested in duplicate. The mean of the results was classified into eight known standard concentrations of Onchocerca gibsoni antigen. Samples with optical density (OD) between standards 1 and 2 were considered to be negative, standard 3 as borderline, and standards 4 to 8 as positive.

Data analysis: The TBF method is considered to have $100 \%$ specificity, but unknown sensitivity because many individuals can harbour adult worms without showing microfilaraemia (mf ${ }^{10}$. Consequently, the sensitivity of the ICT card test can be estimated, but not its specificity. Moreover, the observed prevalence of filariasis is at least $(\mathrm{a}+\mathrm{b}) / \mathrm{N}$ but could be more taking into account the low sensitivity of the TBF (Table 1). Since the specificity cannot be directly calculated, it was estimated as a function of the prevalence of filariasis using the following equation derived by STAQUET et al. ${ }^{23}$. The formula allows calculation of a range of possible values for the specificity of the ICT test based on the observed prevalence of filariasis by the reference test (TBF) and the new test (ICT), and provides a curvilinear relationship between the two unknown parameters, i.e., the specificity and prevalence. 
prevalence $=\frac{(a+b)\left(N \cdot S P_{N}-b-d\right)}{N\left(S P_{N}(a+b)-b\right)}$

where (Table 1), a = number positive according to both TBF and ICT card test

$\mathrm{b}=$ number positive by the TBF and negative by the ICT card test

$\mathrm{d}=$ number negative according to both TBF and ICT

$\mathrm{N}=$ total of individuals examined

$\mathrm{SP}_{\mathrm{N}}=$ specificity of the ICT card test

\section{RESULTS}

Endemic area: Of 687 people living in the households sampled for the ICT card test evaluation, 527 (76.7\%) were submitted to both TBF and ICT card test. In addition, 106 residents in households sampled for the survey that had a member with a positive TBF were also re-checked by the ICT card test. Eight participants had indeterminate results due to the excessive amount of blood dropped on the test line. Among those who had meaningful results, $38(6.1 \%)$ were positive by the thick blood film technique and $198(31.7 \%)$ by the ICT card test. Out of $38 \mathrm{mf}-$ positive persons by the TBF, $2(5.3 \%)$ were negative by the card test, whereas $162(27.6 \%)$ individuals negative by the TBF were positive by the ICT card test (Table 1). The microfilariae load among the mf-positives ranged from 1 to $126 \mathrm{mf} / 60 \mu \mathrm{l}$ (data not shown).

Table 1

Filariasis infection according to the TBF $(60 \mu \mathrm{l})$ and ICT, Olinda, 1999

\begin{tabular}{|c|c|c|c|}
\hline \multirow[t]{2}{*}{ ICT card test } & \multicolumn{2}{|c|}{ Microfilariaemia $(\mathrm{mf} / 60 \mu \mathrm{l})$} & \multirow[t]{2}{*}{ Total } \\
\hline & Positive (\%) & Negative (\%) & \\
\hline Positive & 36 (94.7) (a) & $162 \quad(27.6)^{(c)}$ & 198 \\
\hline Negative & $2 \quad(5.3)^{(b)}$ & $425 \quad(72.4)^{(d)}$ & 427 \\
\hline Total & $38(100.0)^{(a+b)}$ & $587(100.0)^{(\mathrm{c}+\mathrm{d})}$ & 625 \\
\hline
\end{tabular}

There was no statistically significant difference in the prevalence of microfilariae or antigenaemia according to age group. The prevalence of microfilaraemia and antigenaemia were slightly higher in males than females. The overall sensitivity of the whole blood ICT card test was $94.7 \%$ (36/38). The two false negatives were females in the 26-39 year age group (Table 2).

The estimated values for the specificity of the ICT card test ranged between $72.4 \%$ to $100 \%$, based on the prevalence estimated by the TBF and ICT test, respectively (Fig. 1).

Non-endemic area: 110 residents, $39(35.5 \%)$ males and $71(64.5 \%)$ females aged between 10 and 78 years (mean $39.6 \pm$ SD 5.1) were examined. Among them, 78 (70.9\%) were negative and $32(29.6 \%)$ exhibited a slight pink mark at the test line that was interpreted in the field

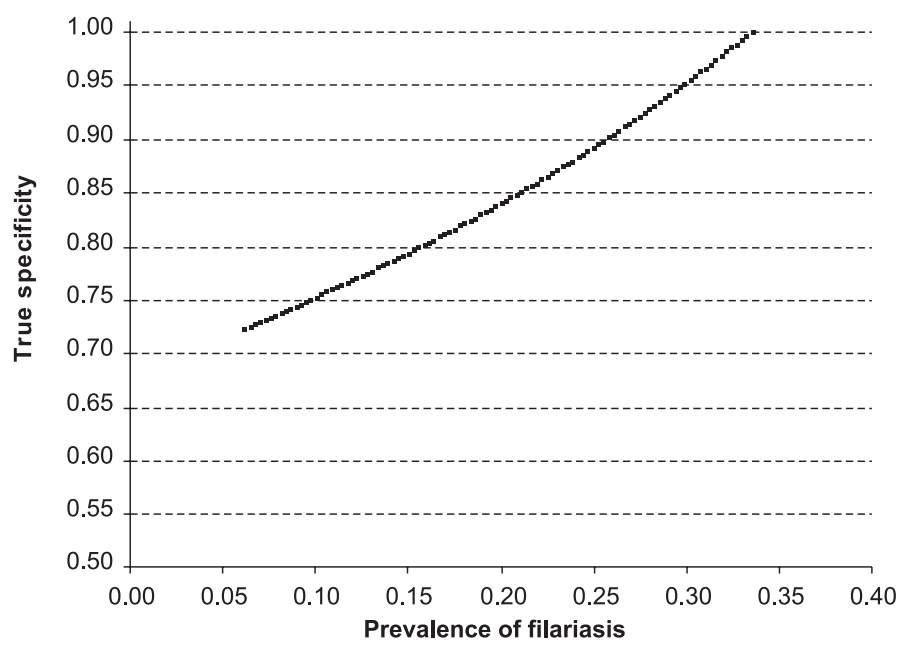

Fig. 1 - True specificity of the whole blood card test according to the prevalence of filariasis

Table 2

Prevalence of microfilaraemia (TBF), antigenaemia (ICT) and sensitivity of ICT card test according to age and sex, Olinda, 1999

\begin{tabular}{|c|c|c|c|c|}
\hline & $\begin{array}{l}\text { Examined } \\
(n)\end{array}$ & $\begin{array}{l}\text { Thick blood film } \\
\qquad(60 \mu \mathrm{l})\end{array}$ & ICT test* & $\begin{array}{l}\text { Estimated sensitivity and } \\
95 \% \text { CI of the ICT test }\end{array}$ \\
\hline & & No. Pos $(\%)$ & No. Pos $(\%)$ & \\
\hline Total & 625 & $38(6.08)$ & 198 (31.68) & $94.7(80.9-99.1)$ \\
\hline \multicolumn{5}{|l|}{ Age (years) } \\
\hline $5-15$ & 160 & $11(6.88)$ & $53(33.12)$ & $100.0(67.9-100.0)$ \\
\hline $16-25$ & 152 & $7(4.61)$ & $47(30.92)$ & $100.0(56.1-100.0)$ \\
\hline $26-39$ & 162 & $14(8.64)$ & $54(33.33)$ & $85.7(56.2-97.5)$ \\
\hline \multirow[t]{2}{*}{$40-65$} & 151 & $6(3.97)$ & $44(29.14)$ & $100.0(51.7-100.0)$ \\
\hline & & $\chi^{2}(3 \mathrm{df})=3.79 p=0.28$ & $\chi^{2}(3 \mathrm{df})=0.84 p=0.83$ & \\
\hline \multicolumn{5}{|c|}{ D } \\
\hline Male & 259 & $21(8.11)$ & 88(33.98) & $100.0(80.8-100.0)$ \\
\hline \multirow[t]{2}{*}{ Female } & 366 & $17(4.64)$ & $110(30.05)$ & $88.2(62.3-97.9)$ \\
\hline & & $\chi^{2}=3.185 p=0.07$ & $\chi^{2}(3 \mathrm{df})=1.07 p=0.29$ & \\
\hline
\end{tabular}

* 8 indeterminate results 


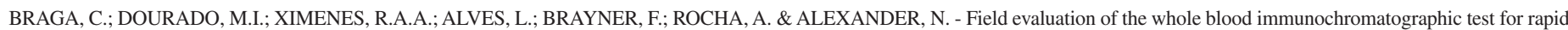
bancroftian filariasis diagnosis in the northeast of Brazil. Rev. Inst. Med. trop. S. Paulo, 45(3):125-129, 2003.

as a positive result in accordance with the manufacturer's instructions. All sera were tested by Og4C3-ELISA and did not show OD values above the standard 1 and 2, confirming the negative infection status.

\section{DISCUSSION}

Sensitivity, specificity predictive values, speed and simplicity are important factors to be considered in assuring efficiency of screening and surveillance for bancroftian filariasis. Therefore, assessing the performance of new diagnostic methods is an important step towards elimination of transmission.

Some studies evaluating the whole blood ICT card test in the field have been performed ${ }^{6,12,15,17}$. However, most of them involve two-stage samples which commonly introduce bias that may affect both sensitivity and specificity estimates ${ }^{20,23}$.

The present study found a high sensitivity of the ICT card test compared with the TBF. The study design, which encompasses the performance of both the ICT card test and TBF in all individuals sampled, as well as the assumption of $100 \%$ of specificity for TBF, allowed for the correct calculation of the sensitivity of the ICT card test ${ }^{23}$. Conversely, the well-known low sensitivity of the TBF frequently leads to considerable classification errors related to the mf-negative status of the individuals.

Imperfect gold standards like TBF usually introduce a series of biases, such as, an underestimation of the prevalence of filariasis, specificity and positive predictive value of the new test, in addition to an overestimation of the negative predictive value. The dimension of these biases will depend on either the sensitivity of the reference test or the true prevalence of the disease in the population ${ }^{23,25}$. For instance, the sensitivity tends to be more accurate when the prevalence of disease is high whereas the specificity is more accurate when the prevalence of disease is $l_{\text {low }}{ }^{25}$. The use of reference tests with assumed higher sensitivity but similar technology, such as Og4C3 ELISA, is sometimes used in order to overcome this problem. However, presence of a non-random relationship of errors (correlated error) between the two diagnostic tests that usually results in a degree of concordance between the two exams higher than expected by chance may appear ${ }^{24}$. This type of error commonly produces an overestimation of the performance of the test. In the present study, this bias was not a problem since the reference test (TBF) has a distinct principle.

It was found that $165(25.7 \%)$ persons negative by the TBF were positive in the ICT card test in the endemic area. Considering the imperfections of TBF, the observed specificity of $72.4 \%[\mathrm{~d} /(\mathrm{c}+\mathrm{d})]$ of the test is possibly underestimated. The ICT card test, in addition to being able to detect microfilaraemic infection, probably identifies early stages of infections and single sex infections. Therefore, part of this group may represent infected individuals that were not detected through parasitological methods. There is also the possibility of false positives since the evaluation of the test in the non-endemic area revealed a considerable number of exams showing faint lines that, following the manufacturer's guideline, were interpreted as positives. The sera from all these persons were antigen-negative by the Og4C3-ELISA, confirming no infection. These findings raised concerns about the specificity of the whole blood card test. Some explanations for the problems can be mentioned. Firstly, the manufacturers diagnostic definition makes the test susceptible to classification errors when interpreting the results, particularly those exhibiting faint lines. Although the reproducibility of the test has not been examined in this study, it seems that borderline results could lead to different interpretations between observers or research groups that may result in different indices of accuracy, i.e., an overestimated sensitivity and underestimated specificity when a lower cut-off is used, or an underestimated sensitivity and overestimated specificity if a higher cut-off is used. Secondly, problems related to crossreaction with geohelminths should also be borne in mind, since the antigens that the test is able to detect have not been clearly identified ${ }^{10}$.

The use of Staquet's formula allowed us to calculate that the specificity of the ICT card ranged between $72.4 \%$ and $100 \%$ depending on the prevalence of filariasis in the population. Therefore, as shown in the Figure 1, a high specificity for the whole blood ICT card test is only obtained when we assume a prevalence of filariasis over $25 \%$.

A cost analysis of the ICT card test was carried out in Sri Lanka. The TBF was shown to have a lower price (ICT cost per unit US\$ 2.75 vs TBF cost per unit US\$ 0.30$)^{6}$. However, certain features of the ICT card test proved to be extremely advantageous: high sensitivity, the ability to offer prompt diagnosis, no need for complicated laboratory procedures, and no need for specialised technicians. These combined characteristics overcame the lower price of the TBF, making to be the overall more cost-effective option, thereby justifying its use as a diagnostic tool in screening in endemic areas.

On the other hand, the test does not seem suitable for follow-up and evaluation of control programmes because a considerable number of infected individuals remain antigen positives for more than two years after DEC treatment ${ }^{7,21}$. Since the prevalence of filariasis tends to fall while applying the control measures, it becomes important to utilise tests with higher specificity and, consequently, higher positive predictive value. The use of such methods will allow interventions to be directed to the infected individuals who are responsible for maintaining the chain of transmission in focal areas.

More studies evaluating the performance of the whole blood card test are necessary to verify indices of accuracy under different diagnostic criteria, for instance, considering faint lines either as a positive or negative result. In addition, studies designed to take account of the problems arising from imperfect 'gold standards' are essential, as is a sounder diagnostic definition for the whole blood ICT card test. It would be useful if the manufacturers could give more specific details about the method and antigen applied in the test, as well as further information related to the correct interpretation of the tests in the case of extremely faint lines.

\section{RESUMO}

\section{Avaliação do teste imunocromatográfico (“'ICT card test”) no diagnóstico da filariose em estudos populacionais}

Este estudo avaliou o teste imunocromatográfico ("ICT card test") em inquérito de filariose realizado no município de Olinda, Brasil. 625 pessoas foram examinadas pela técnica da gota espessa (GE), e "ICT card test" (ICT). Moradores do município de Campina Grande, Paraíba, 


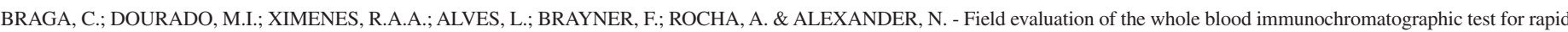
bancroftian filariasis diagnosis in the northeast of Brazil. Rev. Inst. Med. trop. S. Paulo, 45(3):125-129, 2003.

área não endêmica, foram examinados pelos testes ICT e Og4C3-ELISA, para verificação da especificidade. A sensibilidade do método foi de 94,7\%. O desenho do estudo - que envolveu a acurácia do ICT e do teste de referência (GE), em todos os elementos da amostra, - e a especificidade de $100 \%$ da GE permitiram o cálculo correto da sensibilidade. Todavia, como a sensibilidade da GE é desconhecida, a especificidade do ICT é ignorada. É possível, contudo, estimar o limite superior e inferior da especificidade e relacioná-la à prevalência de doença. Na área endêmica, a especificidade do teste variou entre 72,4\% e 100,0\%. 29,6\% dos exames pelo ICT, realizados na área não endêmica, exibiram coloração tênue, tendo sido interpretados como positivos. Algumas características do método, incluindo alta sensibilidade, rapidez e simplicidade de execução justificam sua utilização em rastreamento de áreas endêmicas. Todavia, detalhes acerca da correta interpretação dos resultados com coloração extremamente tênue, parecem de importância fundamental.

\section{ACKNOWLEDGEMENTS}

The authors are grateful to Professors Andre Furtado and Maria de Fatima M. Albuquerque for the valuable contribution on the discussion of the results; to Wayner Souza for the statistical support in the sampling procedures; Janaina Miranda and Lania da Silva for technical assistance and the team of the Departments of Health of Olinda for the logistic support.

\section{REFERENCES}

1. ADDISS, D. - Lymphatic filariasis. Bull. Wld. HIth. Org., 76(suppl.2): 145-146, 1998

2. BHUMIRATANA, A.; KOYADUN, S.; SUVANNADABBA, S. et al. - Field trial of the ICT filariasis for diagnosis of Wuchereria bancrofti infections in an endemic population of Thailand. Southeast Asian J. trop. Med. publ. Hlth., 30: 562-568, 1999.

3. BRAGA, C.; XIMENES, R.A.; ALBUQUERQUE, M.F.P.M. et al. - Avaliação de um indicador sócio-ambiental utilizado no rastreamento de áreas de transmissão de filariose linfática em espaços urbanos. Cadern. Saúde públ., 17: 1211-1218, 2001.

4. BRITO, A.C.; WILLIAMS, P.; FONTES, G. \& ROCHA, E.M. - A comparison of two Brazilian populations of Culex quinquefasciatus (Say, 1827) from endemic and nonendemic areas to infection with Wuchereria bancrofti (Cobbold, 1877). Mem. Inst. Oswaldo Cruz, 92: 33-36, 1997.

5. ROCHA, E.M.; FONTES, G.; BRITO, A.C. et al. - Bancroftian filariasis in urban areas of Alagoas State, Northeast Brazil: study in the general population. Rev. Soc. bras. Med. trop., 33: 545-551, 2000.

6. CHANDRASENA, T.G.A.N.; PREMARATNA, R.; ABEYEWICKREMA, W. \& de SILVA, N.R. - Evaluation of the ICT whole-blood antigen card test to detect infection due to Wuchereria bancrofti in Sri Lanka. Trans. roy. Soc. trop. Med. Hyg., 96: 6063, 2002.

7. FREEDMAN, D.O.; PLIER, D.A.; ALMEIDA, A.B. et al. - Effect of aggressive prolonged diethylcarbamazine therapy on circulating antigen levels in bancroftian filariasis. Trop. Med. Int. Hlth., 6: 37-41, 2001.

8. FREEDMAN, D.O.; ALMEIDA, A.; MIRANDA, J.; PLIER, D.A. \& BRAGA, C. - Field trial of a rapid card test for Wuchereria bancrofti. Lancet, 350: 1681, 1997.

9. MACIEL, A.; FURTADO, A.F. \& MARZOCHI, K.B. - Views on the municipalization of lymphatic filariasis control in greater metropolitan Recife. Cadern. Saúde públ., 15: $195-203,1999$.
10. NUTMAN, T.B. - Lymphatic filariasis. London, Imperial College Press, 2000. p. 127 150

11. NGUYEN, N.L.; PliCHART, C. \& ESTERRE, P. - Assessment of immunochromatographic test for rapid lymphatic filariasis diagnosis. Parasite, 6: 355-358, 1999

12. NJENGA, S.M. \& WAMAE, C.N. - Evaluation of ICT filariasis card test using whole capillary blood: comparison with Knott's concentration and counting chamber methods. J. Parasit., 97: 1140-1143, 2001.

13. OMAR, M.S.; SHEIKHA, A.K.; AL-AMARI, O.M.; ABDALLA, S.E. \& MUSA, R.A - Field evaluation of two diagnostic antigen tests for Wuchereria bancrofti infection among Indian expatriates in Saudi Arabia. Southeast Asian J. trop. Med. publ. Hlth., 31: 415-418, 2000.

14. OTTESEN, E.A; DUKE, B.O.; KARAM, M. \& BEHBEHANI, K. - Strategies and tools for the control/elimination of lymphatic filariasis. Bull. Wld. HIth. Org., 75: 491$503,1997$.

15. PANI, S.P.; HOTI, S.L.; ELANGO, A. et al. - Evaluation of the ICT whole blood antigen card test to detect infection due to nocturnally periodic Wuchereria bancrofti in South India. Trop. Med. Int. Hlth., 5: 359-363, 2000.

16. PHANTANA, S.; SENSATHEIN, S.; SONGTRUS, J.; KLAGRATHOKE, S. \& PHONGNIN, K. - ICT filariasis test: a new screening test for bancroftian filariasis. Southeast Asian J. trop. Med. publ. Hith., 30: 47-51, 1999.

17. RAMZY, R.M.; HELMY, H.; EL-LETHY, A.S. et al. - Field evaluation of a rapid-format kit for the diagnosis of bancroftian filariasis in Egypt. East Mediterr. Hlth. J., 5: 880-887, 1999.

18. ROCHA, E. \& FONTES, G. - Bancroftian filariasis in Brazil. Rev. Saúde públ. (S Paulo), 32: 98-105, 1998.

19. ROCHA, A.; ADDISS, D.; RIBEIRO, M.E. et al. - Evaluation of the OG4C3 ELISA in Wuchereria bancrofti infection: infected persons with undetectable or ultra-low microfilarial densities. Trop. Med. Int. Hlth., 1: 859-864, 1996.

20. SACKETT, D.L. \& HAYNES, R.B. - Evidence base of clinical diagnosis: the architecture of diagnostic research. Brit. med. J., 324: 539-541, 2002.

21. SCHUETZ, A.; ADDISS, D.G.; EBERHARD, M.L. \& LAMMIE, P.J. - Evaluation of the whole blood filariasis ICT test for short-term monitoring after antifilarial treatment. Amer. J. trop. Med. Hyg., 62: 502-503, 2000.

22. SIMONSEN, P.E. \& DUNYO, S.K. - Comparative evaluation of three new tools for diagnosis of bancroftian filariasis based on detection specific circulating antigens. Trans. roy. Soc. trop. Med. Hyg., 93: 278-282, 1999.

23. STAQUET, M.; ROZENCWEIG, M.; LEE, Y.J. \& MUGGIA, F.M. - Methodology for the assessment of new dichotomous diagnostic tests. J. chron. Dis., 34: 599-610, 1981

24. VACEK, P.M. - The effect of conditional dependence on the evaluation of diagnostic tests. Biometrics, 41: 959-968, 1985

25. VALENSTEIN, P.N. - Evaluating diagnostic tests with imperfect standards. Amer. J. clin. Path., 93: 252-258, 1990

26. WEIL, G.J.; LAMMIE, P.J. \& WEISS, N. - The ICT filariasis test: a rapid-format antigen test for diagnosis of bancroftian filariasis. Parasit. today, 13: 401-404, 1997.

27. WORLD HEALTH ORGANIZATION - Lymphatic filariasis. Fourth report of the WHO expert committee on filariasis. Wld. Hlth Org. techn. Rep. Ser., (702), 1984

Received:30 January 2003

Accepted: 28 April 2003 